\title{
Los judíos de Murcia a través de fuentes municipales. Hipótesis de trabajo
}

\author{
M. ${ }^{a}$ De los llanos Martínez Carrillo *
}

La historia de los judíos murcianos en la Baja Edad Media pasa necesariamente por los trabajos realizados por el profesor Juan Torres Fontes que tienen por objeto directo el estudio de esta comunidad entre los siglos XIII y XV. En el conjunto de toda esta obra hay una interpretación global múltiples veces repetida, que es la referente a la protección concejil dispensada al colectivo de la aljama y a sus individuos aisladamente, constante en el tiempo aunque adaptada a los distintos condicionamientos que la política real en cada etapa y las cambiantes circunstancias sociales imprimían a esta permanente tendencia. Partiendo de esta tesis pretendemos plantear aquí una hipótesis que afectaría a época Trastámara: lo que nos parece período de aguda decadencia de la aljama murciana, comprendido desde 1369 a 1492 está directamente vinculado a la formación de bandos en la ciudad, en cuyas luchas la comunidad judía se vio inmersa y cuyas consecuencias más negativas afectaron por extensión a otras aljamas del reino.

La "delimitación de la judería" y su estudio urbanístico no son completos hasta el momento, aunque su perfil aproximado sí se ha trazado "; sin duda gran parte de lo que en el futuro pueda innovarse en esta parcela del conocimiento dependerá de la arqueología, con consecuencias importantes, además, para la investigación demográfica que se hace igualmente necesaria.

* Universidad de Murcia.

'TORRES Fontes, J., «Los judios murcianos en el siglo XIll», Murgetana, n. 18, 1962, pág. 8 y "Los judíos murcianos a fines del siglo xIv y comienzos del XV», Miscelánea Medieval Murciana, n. ${ }^{\circ}$ VIII, págs. $64-65$. 
La extensión de la judería murciana era relativamente importante respecto a la ciudad cristiana, dado que en ella había una sinagoga mayor ${ }^{2}$ y en consecuencia alguna menor; se conoce igualmente la existencia de un cementerio viejo próximo a la Puerta Nueva de la ciudad, sobre él hubo frecuentes problemas a lo largo del siglo xv, por la violación que hacían de su suelo los cultivadores de las tierras cristianas próximas, al dedicarlo a actividades agrícolas secundarias, así como la localización de su carnicería con corral junto a una torre del adarve próxima a una puerta de la judería, la existencia de horno propio, etc.

En los años sesenta del siglo xv se advierte un proceso de compra de casas fuera de los límites de la judería que razonablemente sólo puede ser imputable a dos factores, las inversiones de capital fuera de su territorio por estar éste saturado y el creciente número de conversos que se estuviesen dando, aunque las actas capitulares digan textualmente en 1473 «... los judios de la juderia, de cada dia se trabajan de aver casas entre los christianos en que moren algunos dellos...», y sin negar la existencia de tiendas de judíos en la ciudad cristiana; el fenómeno continuó en años sucesivos, llegándose en algunos casos a que el concejo anulase las ventas efectuadas ${ }^{3}$. Es notoria la tendencia hacia una más nítida separación espacial y jurídica, que la apertura de una calle «... entre los chrisptianos y judios..." en 1481 hizo más radical al ir acompañada de una orden de clausura de los postigos del barrio judío que diesen a la parte cristiana y de la colocación de puertas en todos los nuevos portales de la judería ${ }^{4}$, como medidas emanadas de la orientación política impuesta por las cortes de Toledo de 1480.

Diversas hipótesis se han construido hasta hoy respecto a la «población» que pudo tener la judería murciana desde mediados del siglo xiv, empezando por los 1.000 habitantes que le calculó Valdeón en el reinado de Enrique II, hasta 1.420 aproximadamente; ninguna de ellas puede proporcionar datos absolutos irrefutables más que en los factores externos al propio crecimiento demográfico, como fueron la llegada de algunos emigrantes judíos procederites de Aragón en torno a 1391, la gran mortandad extraordinaria que supuso la epidemia de peste de 1395-1396 y las consecuencias derivadas de las predicaciones de San Vicente Ferrer

2 Toda la documentación manejada procede del Archivo Municipal de Murcia. Acts. Cap. 1437, fol. $30(12-10-1437)$.

Acts. Cap. 1473, fol. $75(20-11-1473)$ y 1477 , fols. $68(11-11-1477)$ y $71(15-11-1477)$

4 Acts. Cap. 1481, fols. 85 (22-9-1481), 125 (6-11-1481) y 126 (10-11-1481). Documento de la delimitación de Juan de la Hoz en TORREs Fontes, J., Don Pedro Fajardo Adelantado Mayor del Reino de Murcia, C.S.I.C., 1953, doc. LIII. 
en 1411; considerando todo ello Torres Fontes da como posibles unos 1.500 habitantes entre 1391-1395 y desde 1396450 personas menos ${ }^{5}$.

Por nuestra parte seguimos manteniendo la hipótesis que lanzamos en 1978 de una población inferior a los 2.000 habitantes en los comienzos del siglo XV, en torno a los 700 en 1401, 900 en 1408 y 600 en $1411^{6}$, reforzada actualmente por el convencimiento de que a los posibles 2.000 habitantes del reinado de Enrique II les afectó un proceso de conversiones que sin duda es anterior a 1391. Con todas las cuestiones que puedan plantearse en torno a la relatividad de las fuentes fiscales y a la pobreza material de la aljama murciana, estas valoraciones nos siguen pareciendo válidas porque, de momento no hay otras fuentes complementarias y porque la pobreza de los judíos murcianos era relativa si se compara con la mucho más acentuada de los cristianos coetáneos: si muchos judíos quedaron excluidos de pagar impuestos por su pobreza, igualmente lo estuvieron muchos cristianos 0 , posiblemente, más y, por tanto, esta documentación puede ser utilizada en semejantes condiciones para ambas comunidades.

El factor más condicionante de la decadencia demográfica de la judería murciana es la ruptura evolutiva que se opera desde 1411, fecha en la que la población judía de Murcia tocó fondo; la evolución posterior a esta fecha está por valorar, advirtiéndose en la segunda mitad del siglo xv dos circunstancias documentales que hay que confrontar con toda la situación anterior a 1411:

1. ${ }^{\circ}$ La existencia de 150 vecinos de la judería documentados en 1481 y 141 en $1484^{7}$, por tanto no más allá de 700-750 habitantes; Torres Fontes aduce que estas cifras no son reales porque no se incluirían en ellas a las gentes más míseras de la ciudad, entre los que habría judíos ${ }^{8}$; la proporción de judíos pobres de ninguna

5 VALdeón, J., Los judíos de Castilla y la Revolución Trastámaras. Universidad de Valladolid, 1968, pág. 57. MENJOT, D., “L'immigration à Murcie et dans son territoire sous les premiers Trastamares (1370-1420 environs)», Revue d'Histoire Economique et Social, vol. 53, n. ${ }^{\text {os }} 2-3$, 1975. Rosello Verger, V. y Cano, G. M., Evolución urbana de Murcia (831-1973). Ayuntamiento de Murcia, 1975, pág. 58. TORRES FonTES, J., "Los judíos murcianos a fines del siglo XIV...", págs. 95-96.

6 Martínez CARRILlo, M. ${ }^{2}$ LI., Revolución urbana y autoridad monárquica en Murcia durante la Baja Edad Media (1395-1420), Universidad de Murcia-Academia Alfonso X el Sabio, 1980, págs. 53 y 54. 1484).

Acts. Cap. 1480, fol. 78 rev. (9-1-1481) y 229 rev. $(14-4-1481)$ y 1483 , fol. 14 rev. (12-5-

8 TORRES Fontes, J., "Los judíos murcianos en el reinado de Juan Il", Murgetana, n. ${ }^{\circ} 24$, pág. 101. 
manera podía hacer llegar la población absoluta de la judería murciana en las vísperas de la expulsión a cotas sensiblemente más altas.

2. En las anotaciones de vecinos nuevos que registran los documentos existentes, hay un continuo goteo de judíos inscritos como tales durante la segunda mitad del siglo xv, sobre todo a partir de 1460; aunque el estudio aún está por hacer, ser advierte que la mayoría de estos inmigrantes son de Orihuela y otros puntos del reino de Valencia y en menor proporción núcleos murcianos del interior como Mula, y del reino de Granada. Da la impresión de que hubo una corriente inmigratoria importante que no debió de estar contrarrestada con una emigración de intensidad semejante, con la que se hubiese alcanzado el equilibrio entre ambas tendencias, de tal modo que los 700-750 habitantes de los años 1481-1484 eran el resultado de una recuperación demográfica basada en el propio crecimiento vegetativo más la inmigración, ambos fenómenos inevaluables de momento.

Dados estos supuestos documentalmente constatables, no parece verosímil que en los comienzos del siglo xv la judería murciana contara con mucho más de los 600 habitantes posibles después de 1411 .

Aspecto importante del estudio sociodemográfico de los judíos en el reino de Murcia es el conocimiento de sus «relaciones familiares». A los componentes masculinos de la familia se puede llegar a través de la documentación de arrendamientos de rentas concejiles y reales a dos distintos niveles; la diferencia entre ellos es notable dado que, mientras en los primeros nos encontrarmos con operaciones económicas bastante individualizadas, en las que el capital de una persona podía ser suficiente para emprender el negocio con garantías mínimas de seguridad y beneficio, en los segundos en los que el volumen de la masa dineraria manejada era muy superior, varios miembros de una misma familia o incluso de dos familias, aportaban porcentajes del capital complementarios y asociados entre sí; almojarifazgos, alcabalas y más tarde monedas y pedidos ${ }^{9}$, se presentan desde el siglo XIV como una doble fuente de información acerca de la participación cuantitativa de los judíos en estos negocios y del entramado familiar que los sustentaba. Entre estas familias destacan Aventuriel y Cohén, que además de riqueza poseían tradición familiar calificada por Menjot de nobleza para los Aventuriel, que estaban implantados en otras juderías del reino además de la murciana ${ }^{10}$.

9 Martínez Carrillo, M. ${ }^{a}$ LI., "Rentas reales en los comienzos del siglo xV. Arrendadores y recaudadores", Murgetana, n.:54, 1980.

${ }_{10}$ Kohén, sacerdote israelita descendiente de Aharon, OrfaLI LEVI, M., Los conversos es- 
La repetición de connotaciones conflictivas en una misma familia a través del tiempo, presupone el mantenimiento de una actitud respecto a la propia comunidad y respecto a los cristianos, pudiendo ser el aglutinante en torno al cual se forme un estado de opinión extrafamiliar cuyas repercusiones están por investigar y medir. La persona o personas de Rabí León fue centro de diferencias con el concejo de la ciudad de 1454 y 1481, habría que intentar concretar si se trata de uno o dos individuos distintos, en la primera ocasión por diferencias de ámbito de competencias con los oficiales cristianos, que alcanzaron niveles de gran dureza; en 1481 porque fue condenado por "logrero" con otros similares a él quedando encomendado el cumplimiento de la sentencia a los alcaldes de la Hermandad ${ }^{11}$ en los tiempos en que empezaba la guerra de Granada y los préstamos de los judíos se hicieron, desde entonces, absolutamente necesarios hasta los tiempos inmediatos a la expulsión de la comuni$\mathrm{dad}^{12}$. A pesar de que el desmesurado crédito con usura se penaba en abstracto, la ordenanza de 1482 de que quienes hubiesen recibido cualquier bien "... en forma de usura..." lo denunciasen a los alcaldes de la Hermandad, puso en guardia a la aljama representada por dos miembros de la familia Aventureil, que pidieron la no intervención de la Hermandad en estas cuestiones ${ }^{13}$.

Se plantea la necesidad de concretar el tiempo de relación existente entre Rabí León y los Aventuriel, así como investigar en el tipo de actividades de esta familia desde el siglo XIV hasta la expulsión; todavía el 16 de junio de 1492 el concejo concertaba la obligación de abastecimiento de las carnicerías ciudadanas para el año 1492-1493 con un Aventuriel ${ }^{14}$, cuando la inmediatez de la expulsión era un hecho.

Hay aspectos de las actividades judías que nos resultan mal conocidos. Para el reinado de Enrique II Valdeón ya resaltaba entre ellas la agricultura a bajos niveles sociales de la aljama ${ }^{15}$. A lo largo del siglo xv las posesión de «tierras y ganados» por los judíos está muy documentada, de tal modo que se puede hablar de un hecho consolidado y notorio a los ojos de la

pañoles en la literatura rabínica. Problemas jurídicos y opiniones legales durante los siglos XilXVI. Universidad Pontificia de Salamanca-Universidad de Granada-Federación Sefardí de España. Salamanca 1982, págs. 47 y 65. Menjot, D. y González CAStaño, J., «Les Juifs de Mula au XVème siècle (notes socio-demographiques)", Revue des Etudes juives, n. ${ }^{\circ}$ CXLV, enerojunio 1986, pág. 26.

Acts. Cap. 1480, fol. 132 (17-4-1481).

Acts. Cap. 1490, fol. 117 (7-5-1491).

Acts. Cap. 1481, fols. 218 (16-3-1482) y 220 rev. (11-4-1482).

14 Acts. Cap. 1491, fol. 157 (16-6-1492).

15 Valdeon baruque, J., Los judíos de Castilla..., pág. 57. 
población cristiana en la primera mitad del siglo, estando sometidas como todas las demás tierras a la distribución de pedidos reales ${ }^{16}$; pero fue especialmente en la segunda mitad del siglo xv cuando los judíos debieron invertir en tierras con más intensidad ${ }^{17}$.

En 1453 se le calcula a toda la aljama un total de 500 tahullas en la huerta, lo que suponía aproximadamente el 1 por 100 del total de su extensión por aquellas fechas ${ }^{18}$. Desde entonces hasta la expulsión, alguna información se filtra a través de la documentación concejil, desde porciones de tierra que apenas llegaban a una tahulla, como la de un Cohén situada junto a la muralla vieja de la ciudad y próxima a la propia judería ${ }^{19}$, hasta 20 tahullas que el arrendador de la sisa de la carne y el pescado de 1463, Samuel Aventuriel, tenía en la acequia de Roayma o Rumía con las cuales ejercía la fianza ante el concejo por 138.510 maravedís a que ascendía el arrendamiento de aquel año ${ }^{20}$. La utilización de la tierra como inversión de la que se esperaban unos rendimientos inmediatos debía ser el objetivo primordial al que los judíos no renunciaban, antes, al contrario, se renunciaba a la tierra como hizo en 1469 David Abenalfacur que devolvió al concejo 10 tahullas con riego que tenía en la acequia de Alquibla, porque le resultaba antieconómico pagar el cequiaje correspondiente más las frecuentes derramas exigidas para costear las obras del azud mayor del río ${ }^{21}$.

El proceso de adquisición de tierras en el regadío fue evidente, llegándose en 1481 a las 659 tahullas, con las cuales se rebasaba el porcentaje de 1453 a alcanzar el 1,25 por 100 de las 52.579 tahullas que la huerta tenía por entonces ${ }^{22}$. Entre las tareas principales que quedan en este campo de la investigación ésta llega a conocer como explotaban los judíos estas tierras porque, aunque básicamente el sistema era el mismo

16 Acts, Cap. 1438, fol. 62 rev. (21-3-1439). Martínez Carrillo, M. ${ }^{a}$ LI., «Servicios castellanos y política municipal (1420-1450)", Miscelánea Medieval Murciana, n. XIV, 1987-1988, pág. 297.

17 Angus Mackay afirma para esta época que eran bastantes los judíos ganaderos y terratenientes, "Documentos para la Historia de los financieros castellanos de la Baja Edad Media 1: una Información de 23 de septiembre de 1466", Historia. Instituciones. Documentos, n. 5. Sevilla 1978, pág. 322.

18 La aljama participó colectivamente en la reconstrucción del azud mayor del Segura en 1453 con $2.000 \mathrm{mrs}$. correspondientes a las 8 blancas por tahulla que cada propietario pagó (la tahulla equivale a 0,1118 Has). Acts. Cap. 1453, fol. $16 \mathrm{rev}$. (27-7-1453).

19 Acts. Cap. 1461, fol. 40 (31-10-1461)

20 Acts. Cap. 1463, fol. 17 rev. (3-7-1463).

21 Act. Cap. 1468, fol. 114 rev. (30-5-1469).

22 Act. Cap. 1480, fol. 174 rev. (19-6-1481). Torres FonTEs, J., Estampas de la vida murciana en la época de los Reyes Católicos. Murcia, Academia Alfonso X el Sabio, 1984, pág. 242. 
que en el conjunto de los riegos de la huerta a la que pertenecían y de la que dependían, el tipo de relación sociojurídica que mantuviesen con sus explotadores y el objetivo de las mismas nos resultan básicamente desconocidos.

En el secano también tenían tierras los judíos, cuya función primaria era la utilización como pastos para los ganados lanares que muchos de ellos poseían y con los que negociaban como arrendadores que fueron de las carnicerías de la ciudad durante gran parte del siglo XV.

De la importancia de esta actividad, baste decir que con ocasión de la estancia de los Reyes Católicos en la ciudad en 1488 siete grandes propietarios de ganados se obligaron ante el concejo para que el abastecimiento carnicero estuviese asegurado, dos de ellos eran judíos y uno, Isaaq Aventuriel, declaraba 650 cabezas, frente a las 400 del arcediano y otras tantas del deán del obispado; solamente "los Jacas" y Francisco Escarramed les superaron ampliamente con 1.200 cabezas cada uno, mientras que el rebaño más modesto era el de Abusyn Cohen que solamente era de 300 cabezas ${ }^{23}$. Aún teniendo en cuenta que todos estos rebaños estaban integrados por los rebaños más modestos de otros propietarios, reunidos bajo la dirección y protección del principal de todos ellos ${ }^{24}$, como el hecho afectaría tanto a los ganados de judíos como de cristianos, los términos de esta somera comparación siguen siendo válidos.

Como institución con entidad perfectamente definida «la aljama» murciana fue perdiendo posibilidades de acción autónoma a lo largo del siglo $x v$, en un fenómeno paralelo al que estaban sufriendo otras aljamas del reino de Castilla, entendiendo por autonomía la conservación de unas pautas de conducta organizativa jurídico-religiosa en la línea expuesta por Monsalvo Antón ${ }^{25}$, que se fueron deteriorando conforme la autoridad de los oficiales reales se iba imponiendo.

En 1419 la intervención del lugarteniente del adelantado mayor Ruy López de Dávalos para nombrar "regidores judíos" dio lugar a una con-

${ }^{23}$ Acts. Cap. 1487, fol. 101 rev. (11-3-1488). Martínez Martínez, M., La industria del vestido en Murcia (siglos XII-XV). Murcia, Academia Alfonso X el Sabio-Cámara de Comercio, Industria y Navegación. 1988, pág. 22.

24 Martínez CARRILLO, M. ${ }^{2}$ LI., «La ganadería lanar y las ordenanzas de ganaderos murcianos de 1383", Miscelánea Medieval Murciana, vol. IX, 1982. Con referencia al rebaño de Isaaq «el sevillano", vecino de Lorca, está documentada la participación en él de sus "aparceros", Acts. Cap. 1451, fol. 33 rev. (9-3-1452); «todo omme que oviere de L. ${ }^{a}$ oveias a asuso fagasse aparcero con otros fata II mil oves", CEJADOR, J., Vocabulario medieval castellano. Visor, 1990.

${ }_{25}$ Monsalvo Antón, J. M., "Cortes de Castilla y León y minorias", Las Cortes de Castilla y León en la Edad Media, Cortes de Castilla y León, vol. II. Valladolid 1988. 
frontación entre aljama, concejo de la ciudad y adelantado en la que se puso de manifiesto el intervencionismo del oficial real para controlarla y por otro lado la división que presentaban los judíos entre los partidarios de aceptar estos nombramientos y los contrarios a ellos ${ }^{26}$; esta carencia de unidad interior fruto de la diversidad social y económica y de factores internos que no siempre emergen de la documentación cristiana mermó su capacidad de defensa a lo largo del siglo $\mathrm{xv}$, a pesar de que planteamientos institucionales muy concretos se resolviesen a favor de los oficiales judíos de acuerdo con una legislación que los protegía, como el enfrentamiento entre los alcaldes ordinarios de la ciudad y el de los judíos solventado por el concejo a favor del segundo en 1439, que consideraba de su competencia todos los casos en los que participasen judíos y cristianos, fuese quien fuese la parte demandante, mientras que los alcaldes de la ciudad pretendían arrebatarle aquellos casos en los que la demanda fuese interpuesta por los cristianos ${ }^{27}$.

Sucesos que empezaron siendo cuestiones bilaterales entre dos familias 0 , incluso, entre individuos de una misma familia, desbordaron el plano familiar y de la aljama para llegar al ámbito del concejo cristiano; el caso de los hijos del cirujano don Mayr Axaques en los finales del siglo XIV movilizó a tan alto número de judíos que no es verosímil que tras ello sólo hubiese las heridas ocasionadas por dos pendencieros miembros de la aljama a un convecino y, además, la amenaza a algunos de los más representativos miembros de la comunidad de entregar las llaves de la judería y abandonar la ciudad era una postura demasiado radical para unos hechos aparentemente tan primarios ${ }^{28}$; más bien parece la confrontación entre dos facciones desiguales en la que la mayoritaria acusa al concejo de complicidad con la minoritaria, el grupúsculo que personificaban los hijos de don Mayr, todo ello en el duro contexto de la lucha civil ciudadana de 1391-1399.

De caracteres y oportunidad semejantes fueron los hechos desarrollados en agosto de 1454, a menos de un mes de la muerte de Juan II, en los que de nuevo quedaron de manifiesto tensiones internas en torno a la disputa con el concejo sobre a quien correspondía administrar y organizar la participación de la aljama en las obras del azud mayor que se

Acts. Cap. 1419, fols. 7 rev. $(21-12-1419)$ y 23 (13-1-1420).

Acts. Cap. 1439, fol. 21 rev. (5-9-1439) .

28 Acts. Cap. 1397, fols. 89 (29-10-1397), 92 (3-11-1397) y $101 \mathrm{rev}$. (20-11-1397). TORRES Fontes, J., Estampas medievales, Academia Alfonso X el Sabio, 1988, pág. 492 y MARTínez CARRILlo, M. ${ }^{2}$ LI., Revolución Urbana..., pág. 59. 
hicieron necesarias tras la inundación de 1452 o posteriormente enjuiciar los incumplimientos, sí al àlmotacén concejil o a los jueces judíos ${ }^{29}$.

Es preciso hacer planteamientos a fondo para discernir hasta que punto la aljama conservó su autonomía intacta a lo largo del siglo xv o, por el contrario, se vio deteriorada y porqué causas, ya que el hecho de que en 1477 los judíos se quejasen ante el concejo de que se les exigiese poseer treinta espindargas a los individuos más acaudalados de entre ellos y no se considerasen obligados a esta cooperación en la defensa de la ciudad ${ }^{30}$, parece marcar un hito en el mantenimiento de la autonomía, que por entonces estaría circunscrita a asuntos absolutamente domésticos e internos y siempre que no trascendieran y repercutiesen en la sociedad cristiana.

La pérdida de población de la aljama a lo largo del siglo xv facilitó su proceso de debilitamiento, compatible sin embargo con la potencia de algunas de sus individualidades, y en este debilitamiento continuado hay que sopesar la incidencia que supusieron las continuadas conversiones.

La historiografía ha tomado como punto de referencia constante para analizar el gran problema historiográfico de las «conversiones forzadas», el paréntesis temporal que marcan 1391 y 1411; indudablemente los importantes movimientos antijudáicos iniciados en los finales del siglo xIV y las consecuencias colectivas e individuales de las predicaciones de San Vicente Ferrer crearon una fuerte tenaza de presión sobre la comunidad judía costosa de superar, que sería de difícil interpretación aisladamente sin analizar de forma precisa la trayectoria que condujo a aquellos hechos.

Las conversiones anteriores a 1391 en Murcia precisan de un estudio metódico y pausado porque no emergen de la documentación por sí mismas, por el contrario, la excepción es encontrarlas explicitadas. Cabe plantearse hipotéticamente que si Arnao Sánchez de Moncada «... que se torno christiano...» el 5 de febrero de 1387 recibía 100 maravedís del concejo para ayuda de su incorporación al mundo de los cristianos, debido a que se había convertido voluntariamente y «... era buen sabidor de la ley..." ${ }^{31}$, se estaba estimulando con su ejemplo a la aljama, que un tan buen entendedor de la ley tendría un alto status dentro de ella y en modo alguno sería el único caso de abandono que hubiese sufrido la comunidad; por el nombre adoptado como cristiano se deduce su relación con una familia, los Moncada, que desde muy pronto estuvo ligada al nuevo

Acts. Cap. 1454, fols. 24 rev. (20-8-1454), 25 rev. (24-8-1454) y 33 (19-10-1454).

Acts. Cap. 1476, fol. 131 rev. (3-6-1477).

Acts. Cap. 1386, fol. 105 (12-2-1387). 
poder que desde 1369 se empezó a introducir en el reino de Murcia, el de los Fajardo a cuya causa se vincularon desde el primer momento y en cuyos negocios el judío había participado anteriormente en relación con genoveses ${ }^{32}$; ¿se convirtió «.... por su voluntad...»? o los Moncada y los Fajardo presionaron en este sentido a los elementos de la comunidad judaica en contacto con ellos?; cabe dudar de esa espontaneidad en la conversión, si se asume que la coacción fue el principal móvil de las conversiones bajomedievales ${ }^{33}$.

Es importante este caso puntual como ejemplo de la atmósfera que se estaba respirando respecto a los judios en la ciudad de Murcia, pero no se puede simbolizar en el concejo a toda ella, ni antes ni después de «1391», año en el que en la sociedad murciana se produjo un gran desgarramiento social con la «ruptura en dos bandos» que habían estado preparándose desde mucho tiempo atrás, los Manuel y los Fajardo, la vieja nobleza arruinada con apoyo de clases sociales muy afectads por la crisis y la nueva nobleza emergente del propio marasmo sociopolítico de los finales del siglo xIV; los primeros acantonados en la ciudad hasta 1399 y los segundos expulsados de ella el 22 de julio de 1391, tres días antes de la fecha en que tradicionalmente se producía el relevo anual de regidores ${ }^{34}$.

Hay por tanto una coincidencia cronológica casi completa entre el comienzo de la lucha civil en la ciudad y el reino de Murcia y el de los grandes movimientos contra los judíos iniciados el 6 de junio en Sevilla y el 9 de julio en Valencia y posteriormente reproducidos en tantas ciudades; ante ello el planteamiento historiográfico es el de la reacción ante el problema judío de los dos bandos murcianos en lucha, uno de los cuales dominaba el concejo, dos bandos cuyos componentes sociales no eran semejantes desde el vértice a la base de cada uno de ellos.

1. El bando intraurbano, los Manuel, toleró a los judíos y más a los conversos, utilizándoles porque los necesitaba en su aislamiento, pero los mantuvo en un estricto control, tanto en su territorio de la judería como a nivel general, control simbolizado en la orden de que los cristianos

32 Martínez Carrillo, M.a Ll., Manueles y Fajardos. La crisis bajomedieval en Murcia. Academia Alfonso $X$ el Sabio, 1985, pág. 89.

33 Orfati LeVI, M., Los conversos españoles..., pág. 14. Entre 1369 y 1370 hubo en Murcia un movimiento contra los judíos en el que resultó víctima un Axaques; Almodóvar del Río 1370VII-9. Pascual Martínez, L., Colección de documentos para la Historia del Reino de Murcia, VIII. Academia Alfonso $X$ el Sabio-C.S.I.C., 1983, doc. LVII.

${ }^{34}$ Martínez Carrillo, M. ${ }^{a}$ Ll., Manueles y Fajardos..., pág. 128. 
nuevos se apartasen de los límites de la judería para evitar una promiscuidad sospechosa con sus antiguos correligionarios ${ }^{35}$.

Esta utilización de los judíos por los Manuel no era nueva, sino la continuidad de la trayectoria seguida en este sentido por el adelantado Juan Sánchez Manuel, conde de Carrión, desde el reinado de Enrique $\|^{36}$, pero sin duda desde el comienzo de la lucha civil se hizo más evidente; con los cultivos permanentemente amenazados por el bando contrario, sin recursos suficientes y negándose a pagar todos los impuestos emanados de la Corona, de los judíos dependió más que nunca desde 1391 la recaudación de la principal renta concejil, los comunes de la carne y el pescado y, a menudo, el abastecimiento de productos alimenticios en cuyo comercio participaban muy directamente ${ }^{37}$; pero dentro de estas actividades estuvieron controlados fuertemente, de tal modo que si el fiel del almojarifazgo de 1395, David Aventuriel, fue obligado a entregar a las monjas de Santa Clara 200 maravedís como parte de la limosna que tenían concedida por los reyes, fue porque Aventuriel se negó en principio aduciendo su nombramiento real y no concejil y sólo con la amenaza de cárcel accedió a la exigencia ${ }^{38}$.

La defensa que los judíos murcianos encontraron en el obispo don Fernando de Pedrosa, argumentada por Torres Fontes como pieza medular que explica, junto a lo que el autor interpreta como protección concejil, el que no sufrieran persecuciones en Murcia en tiempos tan difíciles ${ }^{39}$, es interpretado aquí como la postura exigida por el alineamiento del obispo en un bando concreto al que estaba unido por lazos familiares, los Manuel; si bien es cierto que los casos de defensa personal de los judíos ejercidos por el concejo se dieron, no lo es menos que están igualmente documentados los casos de presión como el ya citado del almojarife Aventuriel o la dificultosa venta que hizo el converso Alfonso de Limiñana, vecino de Orihuela, de las casas que tenía en la judería de

35 Act. Cap. 1392, fol. 74 (14-8-1392). Las sospechas afectaban también a los cristianos nuevos de origen musulmán que llegaban a la ciudad con sus familias, a los que en 1393 se les prohibía que se fuesen de la ciudad hacia Granada sin licencia, bajo pena de expropiación de sus bienes y reducción a cautividad. Act. Cap. 1393, fol. 119 (8-11-1393).

${ }^{36}$ Martínez Carrillo, M. ${ }^{a}$ Ll., «Las aduanas murcianas en el reinado de Enrique II», Homenaje al Profesor Juan Torres Fontes. Universidad de Murcia-Academia Alfonso X el Sabio, $t$. II, 1987, pág. 992.

37 Martínez Carrillo, M. ${ }^{a}$ LI., Revolución urbana..., pág. 59.

38 Acts. Cap. 1394, fol. 210 (17-5-1395).

39 ToRRES Fontes, J., Estampas medievales..., págs. 47-51 y «Los judíos murcianos a fines del siglo xIV...", págs. 57-63. La problemática en el reino de Valencia en Hinojosa MonTALvo, J., "Los judíos de Elche durante la Baja Edad media", Homenaje al Profesor Juan Torres Fontes. Universidad de Murcia-Academia Alfonso X el Sabio, t. I, 1987, págs. 794-797. 
Murcia ${ }^{40}$, deduciéndose que anteriormente había estado avecindado en esta ciudad y que salió de ella en circunstancias económico-religiosas no suficientemente claras.

Si el concejo, dominado por una facción, toleró e incluso protegió a los judios desde 1391 a 1399, también los utilizó económicamente como los propios judíos argumentaron cuando, regularizada ya la situación política, en 1400 la ciudad se vio obligada a pagar al Rey todos los impuestos que le debía desde 1391, y los judíos pugnaron tenazmente por rebajar la parte que les correspondía y lo consiguieron, aduciendo que se les tomaron cantidades monetarias durante el período citado que debían de ser consideradas como pagos ya efectuados ${ }^{41}$.

2. Frente a la actitud de calculada tolerancia de los Manuel, los Fajardo, aunque fuera del concejo, constituían la otra cara de la moneda respecto al problema judío. En contraposición a los Manuel, de ellos apenas nos han quedado documentos de su propia autoría de los que se pueda deducir directamente su funcionamiento como grupo, pero respecto a su praxis frente a los judíos siempre se desprende el alejamiento físico, los judíos no estuvieron en sus filas más que excepcionalmente, y la prisión, el tormento físico y los altísimos rescates que les cobraban cuando los capturaban, que son suficientemente elocuentes de los métodos que empleaban. La captura de Salomón Aluleyg y Mardonay Axcobar, que habían formado parte de la tropa manuelista que fue a combatir el centro de acción de los Fajardo en Molina Seca, fue seguida de feroces tormentos y el pago de grandes rescates ${ }^{42}$. El alineamiento de los judíos hasta llegar a integrarse en la tropa concejil de los Manuel, representa la toma de postura de su comunidad respecto a la dicotomía social que se abrió entre los ciudadanos en 1391, consecuencia a su vez de dos praxis diferenciadas frente a los judíos: la admisión de una coexistencia forzada por la crisis en los Manuel y el rechazo más directo en los Fajardo condicionando las conversiones desde tiempo atrás.

Fue esta dicotomía convertida en regional guerra de banderías desde julio de 1391, lo que salvó a los judíos murcianos de los tumultos que se

40 Acts. Cap. 1395, fol. 26 (17-7-1395).

41 Acts. Cap. 1399, fols. $157(31-1-1400), 195$ (16-2-1400), $214(2-3-1400)$ y 217 (6-3-1400). Martínez Carfilto , M. ${ }^{a}$ LI., "Servicios castellanos y política municipal. Aspectos fiscales de la reforma concejil murciana de 1399", Miscelanea Medieval Murciana, V, 1980, pág. 35.

${ }_{42}$ Acts. Cap. 1393 , fols. 44 rev. $(5-8-1393), 63$ (12-8-1393), 64 rev. $(15-8-1393)$ y 70 (24-81393). No fueron el único caso documentado en los años posteriores a 1391; algo similar le ocurrió al mercader Samuel Gormesano cuando pasó por Molina Seca en su camino hacia Murcia. Acts. Cap. 1397, fol. 27 (21-7-1397) 
empezaron a dar tanto en Andalucía como en Valencia; el motín urbano enfrentó a dos bandos decantados progresivamente desde 1369 y el hecho de que los Fajardo, los más drásticos frente a los judíos, perdieran el poder de la ciudad en 1391, salvó a la comunidad judía de una violencia semejante a la desatada en otros territorios hispánicos.

A partir de entonces, un factor importante de presión sobre las conversiones fue la influencia de los bandos urbanos, siempre presentes, simbolizada en Juan Bezón, a quien el concejo no le reconoció en 1403 la hidalguía que reclamaba desde su abuelo, por considerarlo judío, y Alfonso del Poyo perseguido de muerte por dos miembros del bando Fajardo, Pedro Gómez de Dávalos y Lope Ruiz de Dávalos ${ }^{43}$, en un tiempo en el que la actividad de los Manuel resurgió de nuevo ${ }^{44}$ y con él sus partidarios y sus tendencias sociales.

Los efectos de las predicaciones de San Vicente Ferrer en $1411^{45}$ fueron muy notorios en dos sentidos, en la exaltación inmediata que produjo y sus prolongadas consecuencias a lo largo de todo el siglo $x v$ haciendo irreversible el proceso de conversiones, puesto que las predicaciones fueron dirigidas no sólo a los adultos, sino a los «moçuelos» fundamentalmente, a los que se enseñaron el padrenuestro, avemaría, credo y salve en una campaña prolongada por las iglesias de la ciudad, encomendada a los sacristanes de las parroquias ${ }^{46}$. Se trató de una predicación planificada desde la base social y demográfica de la comunidad que conectó con la presión ejercida desde el poder por los Fajardo, cuyo símbolo más perfecto fue el boticario converso Alfonso Yáñez Cohén ${ }^{47}$.

Una carta de Juan II de agosto de 1411 patentizaba el estado de inquietud y miedo físico que la comunidad judaica pasó durante las predicaciones que enardecían a los cristianos, «... estan escandalizados contra ellos para los meter a robo, otrosy para los matar o ferir e facer otros muchos males... diciendo que se tornen xristianos por fuerça e contra su voluntad..." ${ }^{48}$; desde entonces la amenaza física sobre las juderías del reino de Murcia debió ser algo real, conato de asalto a la de Murcia en $1413^{49}$ y peligro de la de Cartagena dada la querella interpuesta por

\footnotetext{
43 Acts. Cap. 1403, fols. 66 (18-8-1403) y 72 (28-8-1403).

44 Martínez Carrillo., M. ${ }^{a}$ LI., Revolución urbana..., pág. 154

45 Martínez Carrillo, M. ${ }^{a}$ Ll., Revolución urbana..., págs. 53-60.

Acts. Cap. 1410, fol. 154 rev. (18-4-1411).

Su trayectoria personal ha sido trazada por ToRres FonTEs, J., «Riesgo de lazaq Cohen y ventura de Alfonso Yáñez Cohen», Estudios en memoria del Profesor Salvador de Moxó. Universidad Complutense de Madrid, t. II, 1982, págs. 653-664.

48 Ayllón, 1411-Vlıl-8, Cartulario 1411-1429, fol 2

49 Acts. Cap. 1412, fol. 93 (14-2-1413).
} 
ambas aljamas ante la corte diciendo que los respectivos concejos querían desalojar ambas juderías haciendo cumplir las ordenanzas de doña Catalina de Lancaster ${ }^{50}$.

El paradigma de los conversos murcianos consecuencia de las predicaciones aceleradas desde 1411, que llegó al poder y al status social a partir de esa fecha fue el regidor Lope Alonso de Lorca, miembro del concejo desde la implantación del regimiento vitalicio en 1424, con varios cargos anteriores inmediatos a 1411; es trabajo pendiente poder identificar con un mínimo de riesgo su nombre judío, su actividad como tal, sus relaciones con el poder cristiano, conveniencia, cálculo, ambición o por el contrario miedo a perder lo que tuviese, posición frente a la creciente fuerza de los Fajardo, más temibles desde que Alfonso Yáñez Fajado II fue nombrado adelantado mayor del reino en 1423; al año siguiente Lope Alonso de Lorca era nombrado regidor y durante tres generaciones él, su hijo y su nieto del mismo nombre, ocuparon el mismo puesto con singular rigor y dureza en el cumplimiento de cualquier normativa hasta que en 1490 la Inquisición hizo blanco en ellos y en otro nieto del primer Lope Alonso de Lorca, el alcalde Rodrigo de Arróniz, que fueron inhabilitados por el tribunal y, posteriormente, Lope Alonso restituido por disposición papal en los días inmediatos al decreto de expulsión ${ }^{51}$.

Si bien no hubo matanzas de judíos sí se advierte una creciente animadversión hacia ellos a partir de 1369, paralela a la implantación progresiva de los Fajardo en el adelantamiento mayor y a la formación de una oligarquía controladora del poder de la ciudad, pudiéndose marcar dos períodos en los que la ruptura de la coexistencia estuvo más en peligro:

El primero tras la muerte de Enrique III y durante casi una década que culminaría en el intento de asalto de la judería de 1413; el mes de enero de 1407 fue de gran tensión acumulada; cuando llegó a la ciudad la carta del infante don Fernando de Antequera previniendo contra un levantamiento similar al de $1391^{52}$, en la cárcel de la ciudad ya había tres judíos ingresados, de un total de nueve presos, demasiados para la desproporción demográfica de la judería respecto a la población cristiana, y al cabo de un mes el concejo ordenaba el reparto de las armas que, en su opinión, guardaban los judíos, entre los cristianos que no las tenían ${ }^{53}$. El temor

50 Cuenca, 1412-111-14, Cartulario 1391-1412, fol. 164.

51 Acts. Cap. 1489 , fol. 193 rev. $(9-4-1490) ; 1490$, fol. $65(18-12-1490)$ y 1491 , fol. 122 (17. 3-1492).

52 Toledo 1406-XII-25, Acts. Cap. 1406, fol. 180 (7-1-1407), Cartulario 1391-1412, fol. 7 rev.

53 Acts. Cap. 1406, fols. $174(3-1-1407)$ y 201 (1-2-1407). 
en el concejo era consecuencia de la asimilación por la población de un corpus de ideas y sentimientos en torno a los judíos, estimulado sin duda por los ordenamientos de $1405^{54}$.

El segundo período de peligro fue en la segunda mitad del siglo xv; los incidentes aislados aparentemente anecdóticos y excepcionales respecto a una teórica convivencia, no son tales sino el reflejo ocasional de un submundo peligroso que no emerge de la documentación con toda su fuerza ni con todas sus posibles perspectivas. Los acontecimientos toledanos de $14499^{55}$ que tuvieron un claro origen fiscal están en la raíz de lo ocurrido en Murcia en 1453, cuando Rabí León y Yuçaf Abonafox compraron las casas que habían sido de la moneda para incorporarlas a la judería y los vecinos derribaron las obras que se realizaban en ellas «... a manera de alboroto..." ${ }^{56}$.

Desde entonces las amenazas reales a la judería fueron continuas, siempre teniendo como componente más visible una coyuntura de presión fiscal con la directa intervención de los judíos en ella: en las cuales adelantado mayor ${ }^{57}$ y concejo, éste con resistencias en su seno, trataban formalmente de que no se vulnerara la legislación real. La década de los sesenta del siglo XV fue especialmente dura en este sentido:

1460-1461, obras de reconstrucción del azud mayor del río Segura, préstamos judíos parã realizarlas, subsiguientes derramas de pechos para devolverlos y alborotos contra ellos en junio de 1460 y abril de 1461 , cuando se sabía que algunas personas «... enducidas de espirito maligno querian alboroçar esta çibdad para que la juderia della se pusiese a sacomano...» ${ }^{58}$.

1462, denuncia del adelantado Pedro Fajardo de que existía un «... concierto de robar a los judíos...» y petición de la aljama de que se guar-

54 Mitre Fernández, E., “Los judíos y la Corona de Castilla en el tránsito al siglo xv», Cuadernos de Hisforia. Anexos de Hispania, 3, pág. 361. Torres Fontes, J., "Moros, judíos y conversos en la regencia de don Fernando de Antequera", Cuadernos de Historia de España. Buenos Aires 1960. 42.

55 Benito Ruano, E., Los orígenes del problema converso. El Albir, S.A., 1976, págs. 22 y

5e Acts. Cap. 1452, fol. 49 rev. (30-1-1453). TORREs FonTES, J., «Los judíos murcianos en el reinado de Juan II», Murgetana, 24, págs. 87-88. Protección de Juan II a las juderías asaltadas de Murcia y Lorca, Medina del Campo 1454-VI-15. Torres FonTES, J., Don Pedro Fajardo.., doc. IV.

57 Miembros de la familia Aventuriel eran mayordomos del adelantado mayor Pedro Fajardo, Moisés en 1470 y Salomón en 1482. Acts. Cap. 1470, fol. 19 (10-7-1470) y 1482, fol. 32 (17-81482)

58 Acts. Cap. 1460, fols. 2 rev. (23-6-1460), 87 (9-4-1461), 88 (14-4-1461) y 89 rev. (18-41461) 
dase la legislación referente a «... que judio non puede ser puesto a tormento... ${ }^{59}$.

1464, Muerte de Moisés Exaques, arrendador de la sisa y libras de la carne y el pescado, «... por cobrar los maravedis de la dicha renta lo mato Juan de Madrit, traginero...» ${ }^{60}$.

1469-1470, el arrendamiento había pasado a menos de Yahuda Exaques, que recibía carta de seguro del concejo ante las amenazas que recibían él y sus hijos; en estas circunstancias el que los judíos se armasen como denunciaba en 1470 Diego González de Peñaranda no resulta increíble ${ }^{61}$ en un período de tiempo en el que Europa se caracterizó por una gravísima crisis de subsistencia e inestabilidad endémica en las ciudades ${ }^{62}$, que en Murcia reactivó las luchas de bandos entre varias ramas de la familia Fajardo y, mientras unos asaltaban las juderías, el adelantado en el poder Pedro Fajardo los protegía en una mecánica similar a la desarrollada en los finales del siglo xIV.

Hechos puntuales que se sucedieron posteriormente evidencian la facilidad con la que se podía desatar la violencia en una sociedad plenamente sensibilizada del problema que suponía la proximidad e interacción del judío en su seno; así, la muerte y posterior robo de Yuçaf Sanguera en el camino de Cieza a Blanca por la familia de los Marín ciezanos ${ }^{63} \mathrm{o}$ los malos modos del alcalde Escortell frente al judío Beniaçar, reprendidos por el concejo y sancionados con una semana de prisión en la sala de la Corte por lo que suponían de demérito del oficio, «... porque los jueces non an de ynjuriar a nadie que paresçe ante ellos a juycio e an de ser mas corteses e onestos que otros.... ${ }^{64}$, no porque el judío no los hubiese provocado y merecido.

La base social del reino de Murcia tenía desarrolladas en su seno unos comportamientos de rechazo que en la segunda mitad del siglo XV podían llegar a ser expeditivos; en ellos el componente ideológico estaba incardinado en la problemática social, como demuestra el hecho de que la reglamentación de observancia de fiestas y cultos cristianos afectase a los judíos más directamente desde $1450^{65}$, de forma paralela y en relación

Acts. Cap. 1462, fol. 13 rev. (9-7-1462).

50 Acts. Cap. 1463 , fol. 75 (7-4-1464).

61 Acts. Cap. 1468, fol. 72 rev. (21-4-1469); 1469, fol. 110 (5-5-1470).

62 MACKAY, A., La España de la Edad Media. Desde la frontera hasta el Imperio (1000-1500). Cátedra, 1977, pág. 202

63 Acts. Cap. 1472, fol. $8(30-1-1473)$

64 Acts. Cap. 1477, fol. $111(21-2-1478)$.

65 Acts. Cap. 1450 , fol. 57 (8-12-1450) y 1468, fol. 81 rev. (8-5-1459). TORRES Fontes, J., "Los judíos murcianos en el reinado de Juan II...", pág. 99. 
con el desarrollo de una agresividad manifestada de forma inequívoca. Sobre esta realidad social crecientemente adversa a los judíos, la relación económica del concejo con ellos continuaría siendo a la vez, dependiente y operativa hasta 1492, de modo que base social y relaciones con el poder recíprocamente se estimularon y condicionaron hasta el último momento. 